\title{
Research on the Hill Start Assist of Commercial Vehicles Based on Electronic Parking Brake System
}

\author{
Pai Peng 1 - Hongliang Wang1,* - Xianhui Wang1 - Weihua Wang 2 - Dawei Pi ${ }^{1}$ - Tianle Jia ${ }^{1}$ \\ 1 Nanjing University of Science \& Technology, Department of Mechanical Engineering, China \\ ${ }^{2}$ Nanjing University of Posts \& Telecommunications, School of Electronic Science \& Engineering, China
}

\begin{abstract}
In this study, we aim to develop a logic threshold control framework to improve the hill-start assist quality of the commercial vehicles equipped with the electronic parking brake (EPB) system, while fulfilling the requirements of start safety. First, the desired pressure model and the EPB pneumatic model are constructed; the solenoid valve is controlled by the proposed scheme via the pulse width and frequency modulation (PWM-PFM) control signal according to the pressure error between the desired pressure and the actual pressure deduced from the EPB pneumatic model. Second, the controller is sufficiently evaluated in a variety of slopes, such as $8 \%, 13 \%$, and $18 \%$, and is compared with two existing benchmark controllers in a co-simulation environment involving Matlab/Simulink and Trucksim. The simulation results demonstrate the hill-start effect and the reductions in the parking brake release delay, friction work and starting jerk. Finally, we further validate the effective implementation of the hill-start assist with the proposed controller on $8.2 \%, 13 \%$ and $20 \%$ slopes in the vehicle experiment. Keywords: hill-start assist, electronic parking brake, commercial vehicle, logic threshold control, co-simulation, experiments

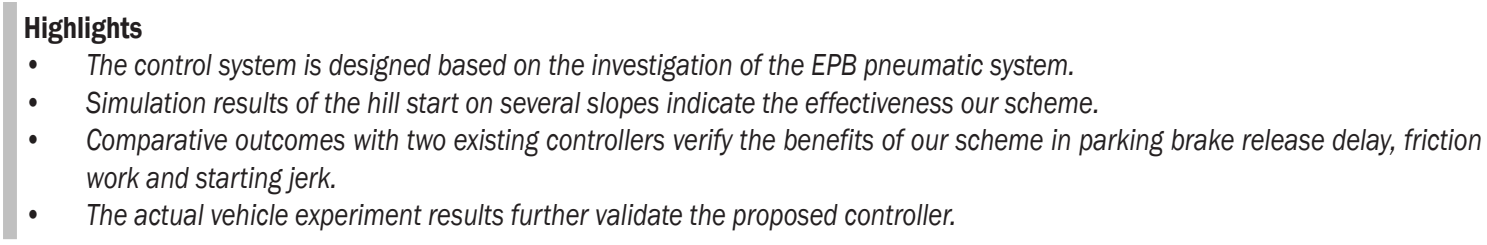

\section{INTRODUCTION}

A frequent situation that causes a serious concern for drivers is starting the vehicle on a hill without any rollback. Hill-start depends on the driver's skill to coordinate with the brake, clutch, and throttle to achieve a smooth start [1], requiring considerable expertise and concentration from the driver [2]. The failure of performing such actions will result in engine stalling, even cause the vehicle to rollback, which leads to the risk of an accident, and may bring stress and panic to the driver. Even for the skilled driver, the frequent manoeuver will aggravate his/her fatigue and increase the possibility of failure [3]. Moreover, the vehicle parts are exposed to abnormal wear if excessive clutch slipping is created during the process in [4] and [5]. The hill-start assist (HSA) system provides the driver with the possibility of starting with safety and comfort by controlling the brake release process [6], without any complex operation and simultaneously avoiding the undesirable effect of vehicle rollback.

Many researchers have done a lot of work on HSA systems and developed different types of HSA systems. An HSA valve in [7] and [8], which is assembled between the master cylinder and the wheel cylinder, is utilized to retain the brake pressure to keep the vehicle stopped while the driver releases the brake pedal and requests enough engine torque to safely start in hill condition. In [9], the authors presented an HSA system for vehicles equipped with anti-lock brake system (ABS)/acceleration slip regulation (ASR) that keeps the brake forces on the wheels by communication with the ABS/ASR control unit, without necessity of keeping the brake pedal actuated. Researchers [10] to [12] investigated the electronic throttle technology on the automated mechanical transmission (AMT) -equipped vehicles; the accelerator pedal was only used to reflect the driver's intention, and the control unit increased the idle speed and engaged the clutch after the brake released. [13] to [15] proposed the hill-start implementation method of the EPB system. The HSA systems described above have been researched considerably mainly from the perspective of HSA function realization, but the control effect issue has not been considered thus far.

In conventional HSA control strategy, the brake starts to release until sufficient driving torque has been generated, which, however, causes excessive clutch friction work and jerk. Wang et al. [16] proposed the Bang-Bang control method of the hillstart functionality of EPB for commercial vehicles, which gradually releases the parking brake according to the increase in the driving torque. However, as 
the parking brake pressure increases, the difference between the two thresholds of the Bang-Bang control will increase and the control cycle will become longer accordingly, which leads to a decrease in the control precision and the release delay of the parking brake.

The primary objective of this study is to develop a logic threshold control framework to improve the hill start quality of an EPB-equipped commercial vehicle in hill start scenarios, while meeting the requirements of start safety. There are three important contributions that clearly distinguish our endeavor from the aforementioned literature:

1. First, the control system model is designed: the desired pressure model and EPB pneumatic system model are constructed; the vehicle model is formulated in Trucksim platform; the proposed controller responds to the pressure error and outputs PWM-PFM control signal for the solenoid valve to regulate the pressure in the parking brake chamber.

2. Second, the co-simulation platform is established involving Matlab/Simulink and Trucksim to verify the effectiveness of the proposed controller under different hill start conditions, including $8 \%, 13 \%$, and $18 \%$ slopes. Several criteria, including brake release delay, rollback distance, friction work and starting jerk, are considered to compare the control effect of the proposed scheme with two existing controllers.

3. Finally, the actual vehicle experiment is carried out on three different slopes, i.e. $8.2 \%, 13 \%$ and $20 \%$, to further demonstrate the effective implementation of our method.

The remainder of the paper is organized as follows: The description of the EPB system is introduced in Section 1. The logic threshold controller design is presented in Section 2, followed by the simulation and the experiment in Section 3. Conclusions are ultimately summarized in Section 4.

\section{DESCRIPTION OF THE EPB SYSTEM}

\subsection{Working Principle}

The architecture of the EPB for commercial vehicles is shown in Fig. 1. On the basis of the original parking brake system of commercial vehicles, the EPB system replaces the manual lever with a switch and adds a solenoid valve to the original pneumatic system. Several sensors have to be strategically positioned on the commercial vehicle to improve the control effectiveness of the HSA functionality of the EPB. Installed at the control port on the relay valve, the pressure sensor is used to indirectly sense the pneumatic pressure of the parking brake chamber. The Hall effect angle sensor is designed to measure the deflection of the suspension to calculate the rear axle load and to acquire the vehicle mass [17]. An accelerometer embedded in the electronic control unit (ECU) is expected to detect the road slope. The ECU receives signals including the switch, controller area network (CAN) bus, pressure sensor pressure feedback and hall effect angle sensor angle feedback necessary to determine the actuation control signal according to the control strategy.

When the driver pushes the switch to release, a signal is sent to the ECU and the ECU activates the solenoid valve to allow compressed air from the air reservoir to go the control port on the relay valve, which opens the delivery ports on the relay valve and then enables the release of the pressurised air already available at the supply port to the parking brake chambers.

As the switch is pulled to apply, any air between the relay valve control port and the solenoid valve is discharged to the atmosphere via the solenoid valve. Then, the air supply from the supply port to the delivery port of the relay valve is cut, and the compressed air in the parking brake chambers is exhausted through the relay valve's exhaust port, assuring the parking brake.

When the vehicle is about to be driven away on a slope, the EPB system's logic checks all the requirements needed to control the release process of the parking brake automatically.

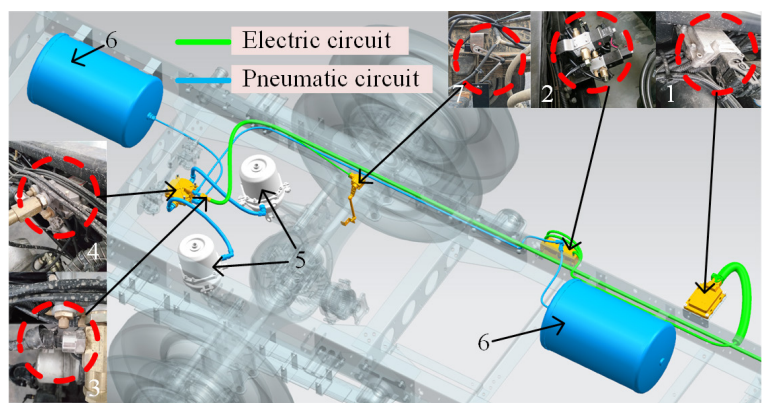

Fig. 1. Architecture of the EPB for commercial vehicles; 1) ECU, 2) solenoid valve, 3) pressure sensor, 4) relay valve, 5) parking brake chamber, 6) air tank, 7) hall effect angle sensor

\subsection{Pneumatic Characteristics}

Fig. 2 shows that with the initial pressure $P_{i n}$ in the parking brake chamber, the solenoid valve is set to open $t_{o}$ to allow the compressed air to pressurise the brake chamber. However, because of the response 
lag of the solenoid valve and the inertia effect of the compressed air, there is a delay and over-inflation in the EPB system.
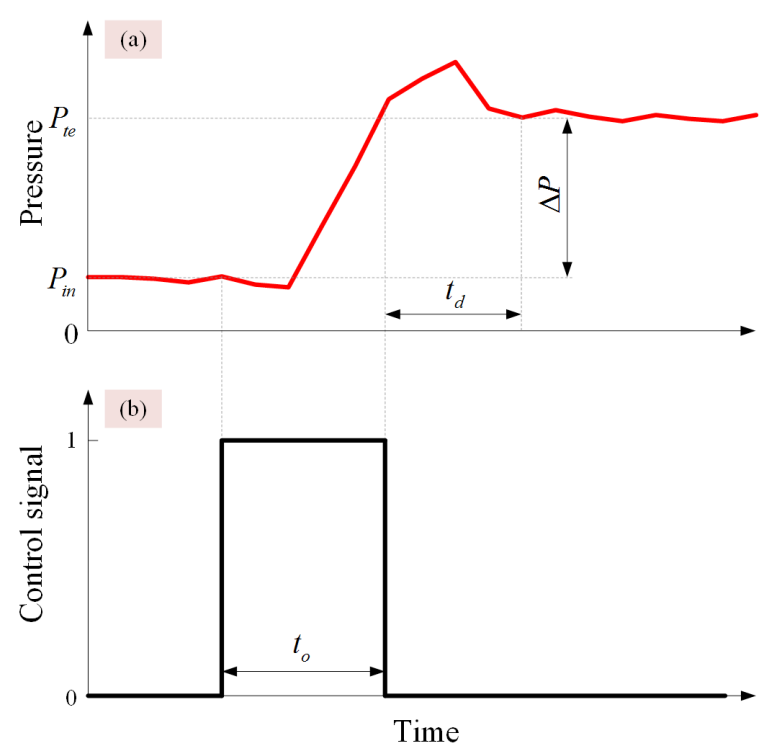

Fig. 2. Typical experimental results; a) brake chamber pressure, and b) control signal of the solenoid valve

With a large number of experiments, the delay time $t_{d}$ is identified to be approximately $40 \mathrm{~ms}$. The pressure increase value $\Delta P$ between before and after the switching action of the solenoid valve decreases with an increase in the initial pressure. Furthermore, the magnitude of $\Delta P$ decides the control mode of the solenoid valve, only when it is in a certain range can the servo control be realized, which will be further discussed in Section 2.

\section{CONTROL SYSTEM DESIGN}

The block diagram of the proposed control system is depicted in Fig. 3. This control system structure contains the desired pressure model, logic threshold controller, EPB pneumatic system model and Trucksim vehicle model. The desired pressure and the actual pressure in the parking brake chamber are denoted by $P_{d}$ and $P$, respectively; their error is represented by $e$. The PWM-PFM control signal for the solenoid valve is referred to as $S . T_{d}$ and $i_{g}$ from the Trucksim vehicle model are the driving torque and the transmission gear ratio, respectively. The main objective of the proposed control system is to make the actual pressure to follow the desired values obtained from the desired pressure model, thereby reducing the release delay of the parking brake. The logic threshold controller responds to the input pressure error and outputs the PWM-PFM control signal for the solenoid valve.

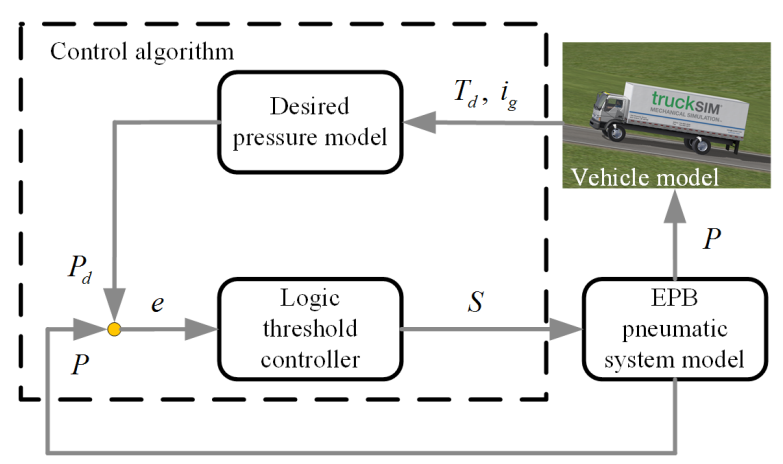

Fig. 3. Block diagram of proposed control system

\subsection{Desired Pressure Model}

Fig. 4 shows that the brake force $F_{X b}$ generated by the parking brake actuators decreases with an increase in the driving force $F_{t}$ during the hill-start process [18]. The parking brake, ideally, should be released entirely at time $t_{1}$ where the driving force $F_{t}$ just overcomes the gradient resistance $F_{t}$; if it is not released in time, e.g. the parking brake is applied continuously until the time $t_{2}$, the brake force $F_{X b}$ will develop into the resistance of the vehicle forward movement during the time period $t_{1}$ to $t_{3}$. A very delayed release of the parking brake in the starting manoeuvre leads to the retardation of the start, creating excessive clutch slipping and serious jerks, which enhances the need for reducing or even eliminating the release delay of the parking brake, under the prerequisite of no rollback, to improve the control effect of the HSA. To capture this requirement, a suitably tailored control strategy for diminishing the brake release delay is proposed to regulate the release process of the parking brake, i.e., releasing the brake gradually as the driving force $F_{t}$, in other words, the driving torque $T_{d}$, increases.

A simplified parking brake system model is developed for the convenience of study. The maximum brake force $F_{X b \max }$ of the parking brake system is expected to be equal to the gradient resistance $F_{i \max }$ on the maximum slope $\alpha_{\max }$ on which vehicle can stop safely, where the pressure $P$ of the parking brake chamber is 0 . The magnitude of the maximum brake force $F_{X b \max }$ can be derived as follows:

$$
F_{X b \max }=m g \sin \alpha_{\max } .
$$

When the parking brake is completely released, the pressure in the parking brake chamber is $P_{0}$. 
The vehicle parking brake system model is thereby simplified as follows:

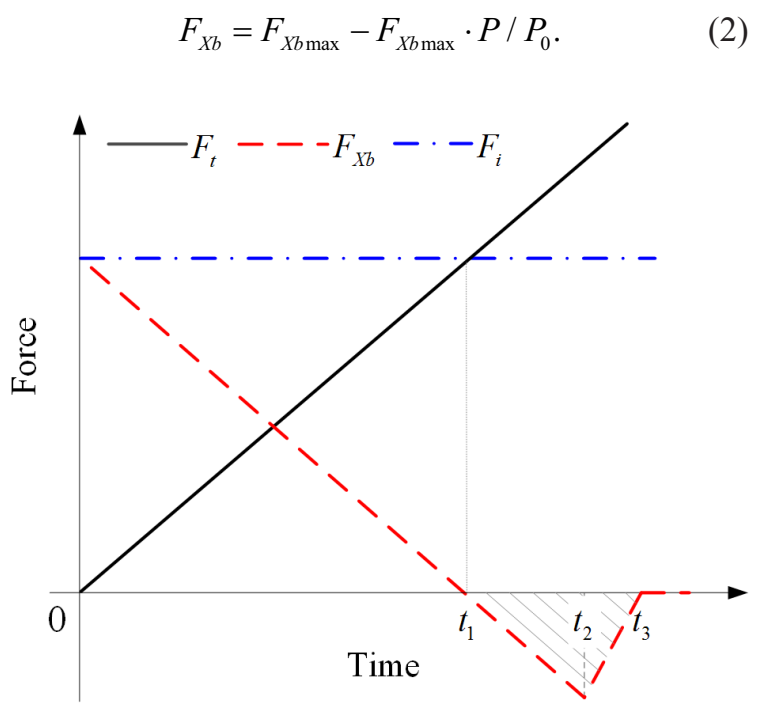

Fig. 4. Forces in the hill-start process

When the vehicle is starting on a low slope $\alpha$, which is less than $\alpha_{\max }$, the maximum brake force $F_{X b \max }$ that the parking brake actuator can provide is greater than the gradient resistance $F_{i}$. Here, to shorten the release delay of the parking brake, a certain amount of compressed air $P_{1}$ released into the parking brake chamber under the premise of a safety start.

$$
P_{1}=\frac{F_{X b \max }-F_{i}}{F_{X b \max }} \cdot P_{0} .
$$

As mentioned above, the parking brake should be released entirely when the driving force $F_{t}$ exceeds the gradient resistance $F_{i}$ in the ideal case. Hence, the following equality has to be fulfilled:

$$
F_{t}=T_{d} i_{g} i_{0} \eta_{T} / r=m g \sin \alpha=F_{i} .
$$

When the driving torque $T_{d}$ is greater than the demand torque $T_{i}$, the solenoid valve is opened to rapidly pressurise the brake chamber to reduce the brake release delay. The demanded torque $T_{i}$ is derived from Eq. (4) as given in Eq. (5):

$$
T_{i}=\frac{m g \sin \alpha r}{i_{g} i_{0} \eta_{T}} .
$$

The desired pressure $P_{d}$ is assumed to be proportional to the driving torque $T_{d}$ such that

$$
P_{d}=P_{1}+\left(P_{0}-P_{1}\right) \cdot T_{d} / T_{i} .
$$

Therefore, the vitally influencing factor in the implementation of the HSA functionality of the EPB-equipped commercial vehicles is to adopt the appropriate control strategy for the solenoid valve, in which the parking brake chamber pressure $P$ will effectively follow the desired pressure $P_{d}$.

\subsection{EPB Pneumatic System Model}

As the solenoid valve is the core component of the EPB system, its dynamic characteristics play a significant role in the performance of the EPB system. When implementing the HSA manoeuver, the solenoid valve of the EPB system can be regarded as an on/ off valve, regulating the air flow to the parking brake chamber by an open/close action.

The dynamic of the solenoid valve [19] includes the electrical circuit model, the magnetic circuit model and the dynamic model of the mechanical components. The electrical circuit model is expressed as follows:

$$
U=I R+N \frac{\mathrm{d} \Phi}{\mathrm{d} t} .
$$

According to Kirchhoff's law, the magnet circuit model is written as follows:

$$
I N=\frac{\delta \Phi}{\mu A_{c}} .
$$

The dynamic model of the mechanical components can be derived as follows:

$$
\ddot{x}=\frac{1}{m_{s}}\left[\frac{\Phi^{2}}{2 \mu A_{c}}-P_{s} A_{s}-K_{s}\left(x+x_{p}\right)-c \dot{x}\right] .
$$

Assuming that air is an ideal gas, heat transfer from the valve orifice is negligible, and shear forces on the walls of the orifice are negligible, the dynamic of the parking brake chamber can be mathematically formulated as follows [20]:

$$
\begin{gathered}
\frac{d P}{d t}=0.0405 C_{d} C_{A} x \frac{P_{u s}}{\sqrt{T}}, \text { if } \frac{P_{u s}}{P_{d s}} \leq P_{c r}, \\
\frac{d P}{d t}=C_{d} C_{A} x \frac{P_{u s}}{\sqrt{T}}\left(\frac{2 \gamma}{R_{g s}(\gamma-1)}\left(\left(\frac{P_{u s}}{P_{d s}}\right)^{\frac{2}{\gamma}}-\left(\frac{P_{u s}}{P_{d s}}\right)^{\frac{\gamma+1}{\gamma}}\right)\right)^{\frac{1}{2}} \\
\text { if } \frac{P_{u s}}{P_{d s}} \geq P_{c r} .
\end{gathered}
$$

The EPB pneumatic system model is illustrated in Fig. 5, and the main parameters of the pneumatic system are listed in Table 1. 


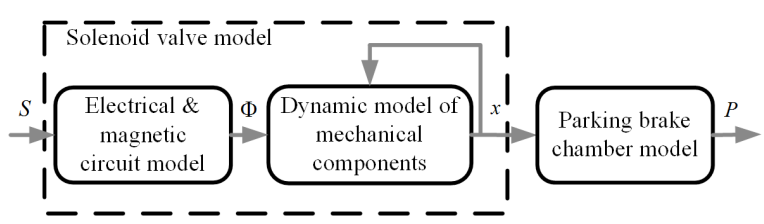

Fig. 5. EPB pneumatic system

Table 1. Main parameters of EPB pneumatic system

\begin{tabular}{cccc}
\hline Parameter & Value & Parameter & Value \\
\hline$U$ & 24 & $N$ & 900 \\
\hline$R$ & 41 & $x_{p}$ & $1.2 \times 10^{-3}$ \\
\hline$\mu$ & $4 \pi \times 10^{-7}$ & $\delta$ & $2 \times 10^{-3}$ \\
\hline$A_{c}$ & $4.72 \times 10^{-5}$ & $c$ & 0.26 \\
\hline$K_{s}$ & $0.77 \times 10^{-3}$ & $m_{S}$ & $0.02 \mathrm{~kg}$ \\
\hline
\end{tabular}

\subsection{Logic Threshold Controller}

From the above analysis, we know that the challenge in the implementation of the HSA is to maintain the desired pressure calculated in Eq. (6); hence, a quick response control strategy of the solenoid valve should be adopted. The logic threshold control method is firstly introduced to the HSA of EPB-equipped commercial vehicles since it only requires to set the reasonable threshold values according to the system characteristics and no need for establishing complex control model, which is suitable for the nonlinear systems. Once the reasonable threshold values are determined, a satisfactory control performance can be obtained. Moreover, it has a strong practicability.

First, according to the pneumatic characteristics of the EPB discussed in Section 1, the delay time $t_{d}$ is maintained at around $40 \mathrm{~ms}$ for the different opening times of the solenoid valve. Therefore, $t_{d}$ is used as the closing time in one control period. The PWMPFM is introduced to control the on/off action of the solenoid valve as it can regulate the duty cycle and the frequency of the control signal at the same time, i.e., by modifying the length of the opening time with the closing time unchanged to regulate the inflation rate and the pressure increase value of the pneumatic system.

The logic threshold control strategy is designed to control the on/off action of the solenoid valve on the basis of the pressure error $e$ between the desired pressure $P_{d}$ and the actual pressure $P$ in the parking brake chamber, as shown in Fig. 6. Three logic threshold values $P_{d}-e_{1}, P_{d}-e_{2}$, and $P_{d}-e_{3}\left(e_{1}<e_{2}<e_{3}\right)$ are set, and each corresponds to the fixed duty cycle and period of the PWM-PFM control of the solenoid valve. When $e \geq e_{3}$, there is a large duty cycle and period of the PWM-PFM control to narrow the error; when $e_{2} \leq e<e_{3}$, the medium duty cycle and period of PWM-PFM control is utilized; and when $e_{1} \leq e<e_{2}$, the small duty cycle and period of PWM-PFM control is designed to precisely track the desired value.
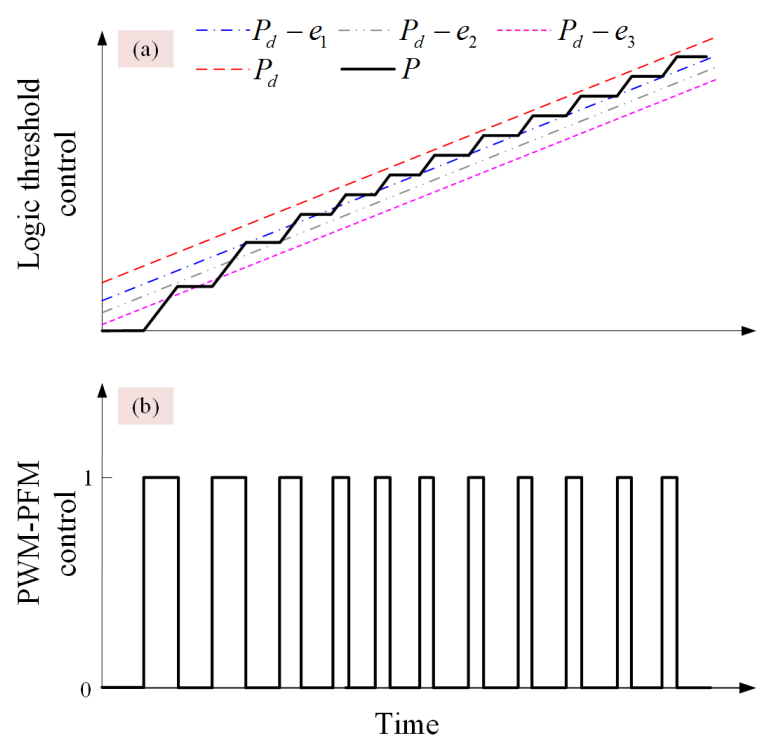

Fig. 6. HSA control strategy; a) Logic threshold control, and b) PWM-PFM control

\subsection{Criteria}

At present, the commonly used evaluation criteria for hill-start include the rollback distance, friction work and starting jerk.

If the vehicle rolls to the unintended direction, there is a risk of accident. To ensure the safety start of the vehicle, the rollback distance is expected to be 0 .

The friction work is the magnitude of the friction work between the pressure plate and the clutch disk in the vehicle start process, influencing the clutch life and reliability. It is calculated using Eq. (12) in [21], as follows:

$$
L=\int_{0}^{t} T_{c}(t)\left[\omega_{e}(t)-\omega_{c}(t)\right] d t
$$

The starting jerk $J$, given by Eq. (13), is the change rate of the longitudinal acceleration of the vehicle, indirectly reflecting the ride comfort of the vehicle.

$$
J=\frac{d a}{d t}
$$




\section{SIMULATION AND EXPERIMENT}

\subsection{Simulation}

To evaluate the performance of the HSA control strategy, a vehicle model is conducted on the Trucksim platform; the main parameters of the vehicle are listed in Table 2. The HSA controller and the EPB system model are designed on the Matlab/Simulink platform; a co-simulation platform is thereby constructed on the basis of the Matlab/Simulink and Trucksim platforms to emulate the hill-start scenarios.

Table 2. Main parameters of the vehicle

\begin{tabular}{cc}
\hline Parameter & Value \\
\hline$m$ & 8190 \\
\hline$r$ & 397 \\
\hline$i_{g}$ & 6.315 \\
\hline$i_{0}$ & 4.875 \\
\hline$\eta$ & 0.99 \\
\hline
\end{tabular}
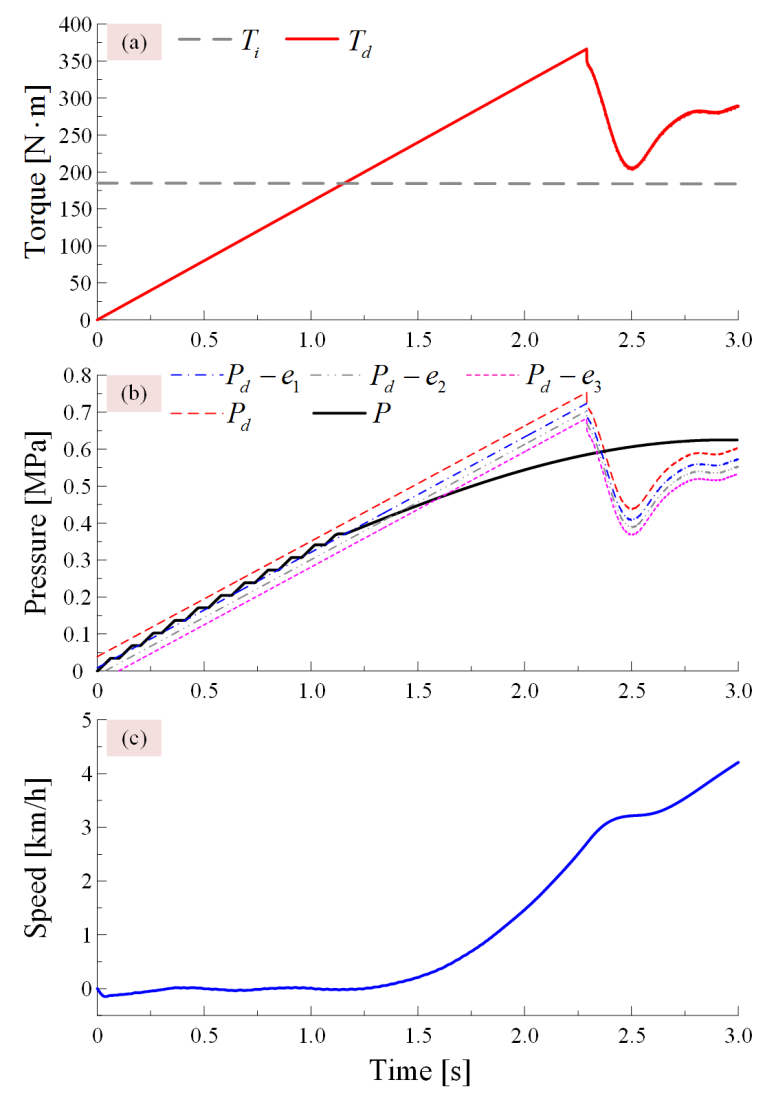

Fig. 7. Simulation results of $18 \%$ slope; a) torque, b) pressure, and c) speed
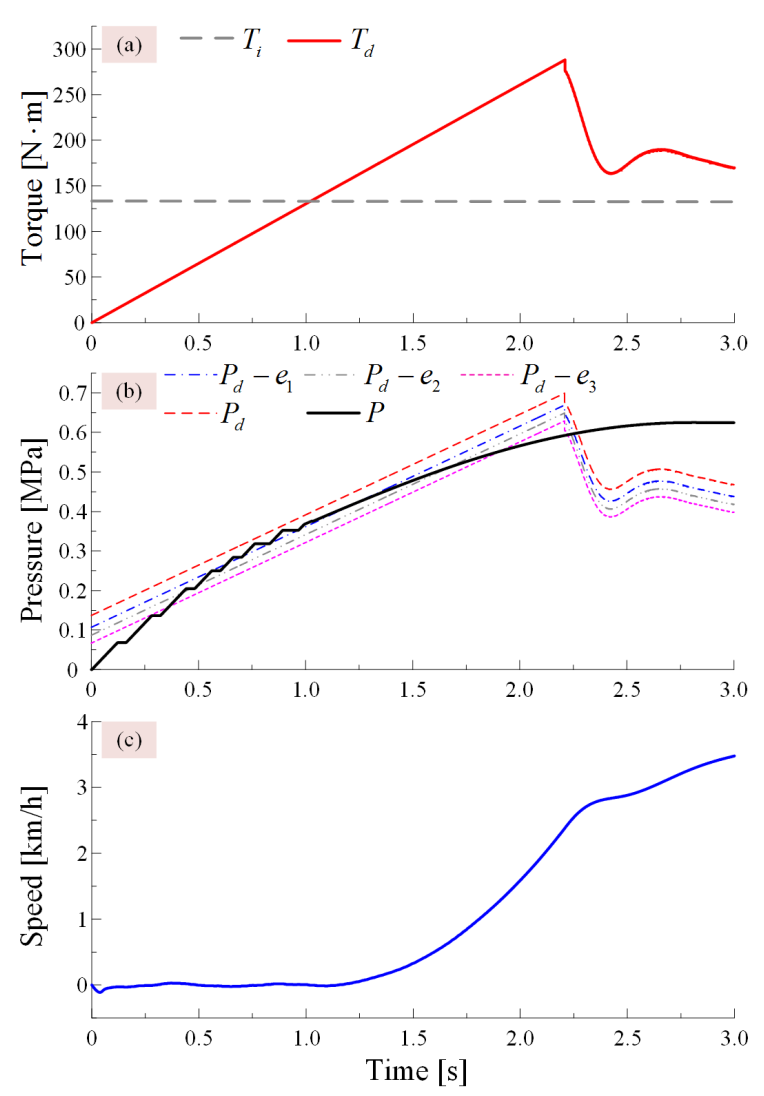

Fig. 8. Simulation results of $13 \%$ slope; a) torque, b) pressure, and c) speed

This section firstly describes the simulation results under three different slope conditions, i.e., $18 \%, 13 \%$, and $8 \%$. When the vehicle is about to start on the $18 \%$ slope, as shown in Fig. 7, the proposed control ensures effective tracking of the desired pressure. When the driving torque just overcomes the demand torque at $1.16 \mathrm{~s}$, the solenoid valve is opened to fast inflate and rapidly release the parking brake. At $1.25 \mathrm{~s}$, the vehicle velocity starts to increase from 0 , suggesting that the logic threshold controller can implement the HSA function of the EPB.

The simulation results on $13 \%$ and $8 \%$ slopes are demonstrated in Fig. 8 and Fig. 9, respectively. It can be seen that the proposed scheme can achieve fast tracking of the desired pressure $P_{d}$ and is able to implement the HSA functionality, verifying the robustness and effectiveness of the logic threshold controller.

The performance of the HSA with the proposed logic threshold controller is compared with that of the two existing ones, namely, the conventional controller developed in [8] and the bang-bang designed in [16]. The bang-bang controller employs the same desired 
pressure $P_{d}$ as that of the proposed controller with two threshold values of $0.9 P_{d}$ and $0.7 P_{d}$. As shown in Fig. 10, when the pressure $P$ is below $0.7 P_{d}$, the solenoid valve is opened to release the parking brake; when the pressure $P$ reaches $0.9 P_{d}$, the solenoid valve is closed to maintain the pressure.
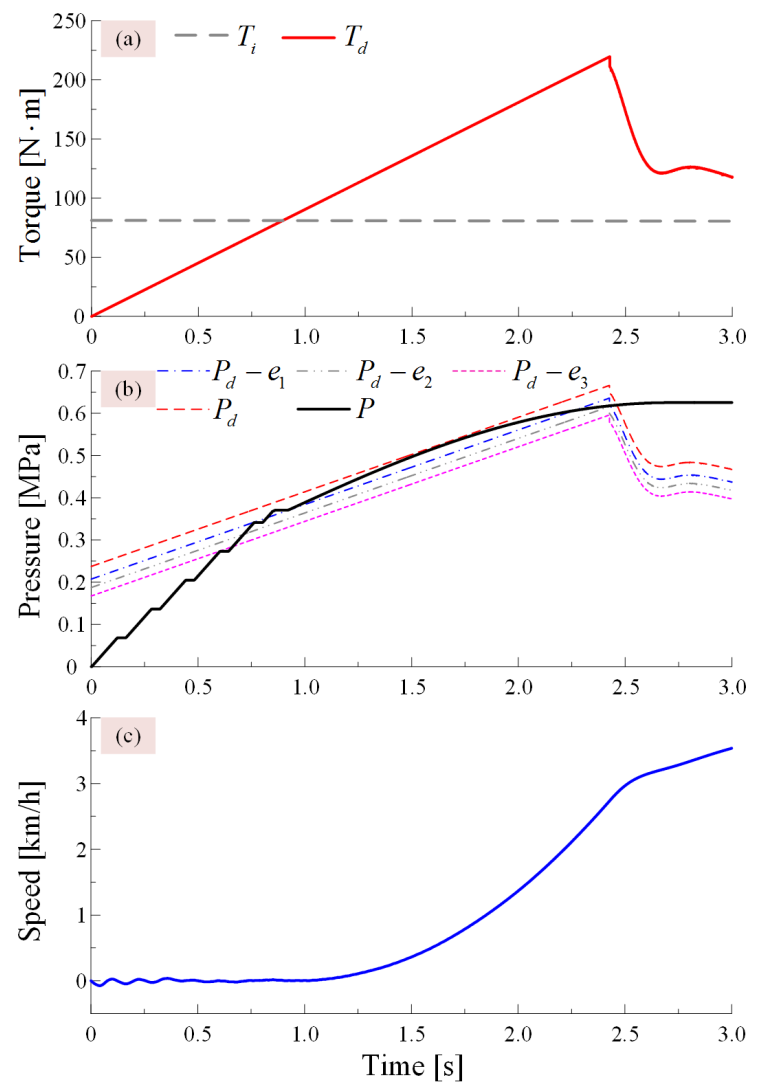

Fig. 9. Simulation results of $8 \%$ slope; a) torque, b) pressure, and c) speed

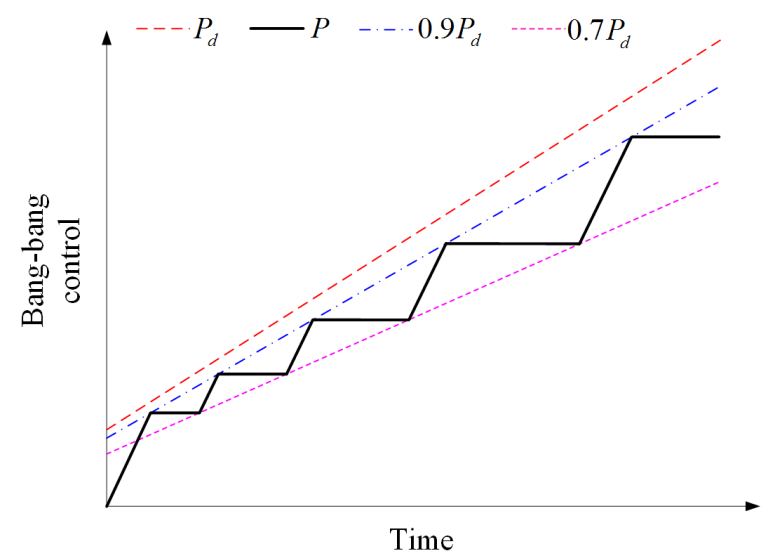

Fig. 10. Bang-bang control

Figs. 11 and 12 illustrate the comparative outcomes of the three controllers on $18 \%$ slope. As depicted in Fig. 11, the parking brake release delay of our scheme, bang-bang control, and conventional control are $0.12 \mathrm{~s}, 0.29 \mathrm{~s}$, and $0.79 \mathrm{~s}$, respectively, showing that the proposed control ensures effective tracking of the desired pressure with a small release delay.

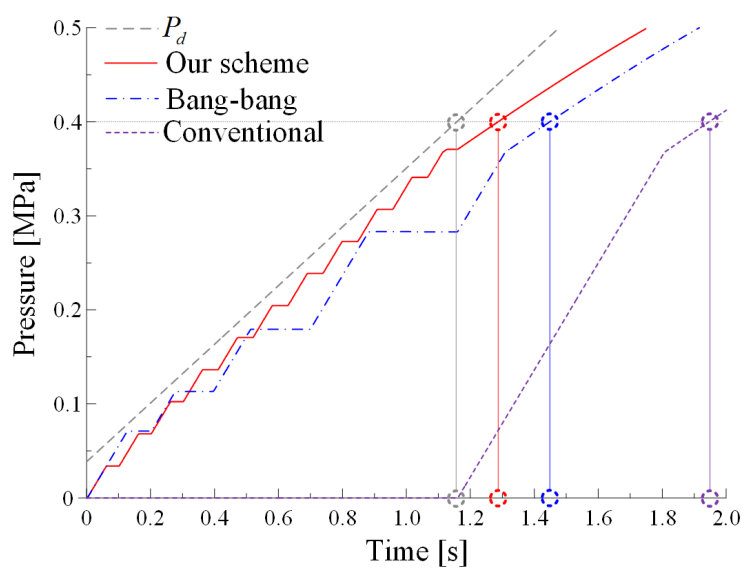

Fig. 11. Comparison with the conventional and the bang-bang schemes in the inflation process
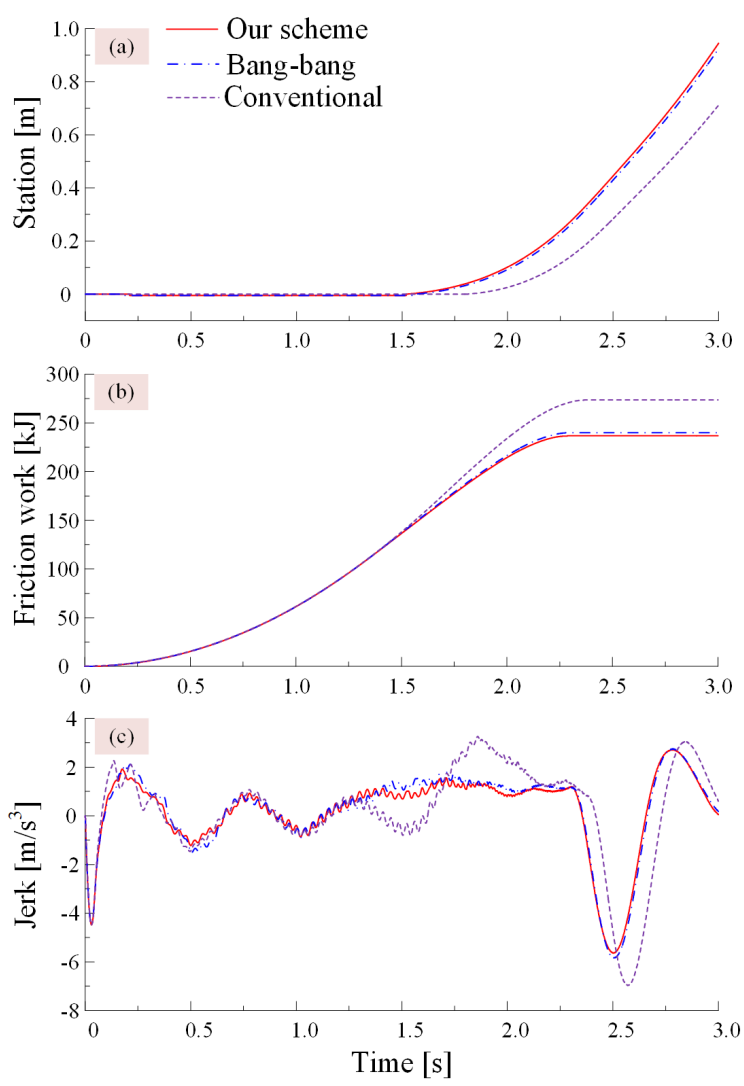

Fig. 12. Comparison with conventional and bang-bang schemes in terms of the following criteria; a) rollback distance, b) friction work, and c) starting jerk 
Fig. 12a shows that there is no rollback with the conventional control, and bang-bang and the logic threshold controller both have an unnoticeable rollback distance of $0.005 \mathrm{~m}$, which suggests that all of the above controllers meet the safety requirements. At the same time, it can be seen that the vehicle starts faster under the proposed controller. The comparative results in terms of the friction work are shown in Fig. 12b. It is evident that the conventional controller generates more clutch friction because of the longest release delay of the parking brake. The increases in the friction work are $15.43 \%$ and $1.38 \%$ in the cases of the conventional and the bang-bang controller, respectively. In Fig. 12c, the proposed scheme outshines its two counterparts from the perspective of the starting jerk. A clearer comparison can be achieved by using the root mean square (RMS) values of the starting jerk. The comparison of HSA criteria for three controllers is summarized in Table 3. It can be discerned that the proposed controller evidently outperforms bang-bang control and conventional control in aspects of brake release delay, clutch friction work, and starting jerk under all three slopes.

Table 3. Comparison of HSA performance for three controllers

\begin{tabular}{clcccc}
\hline \multirow{2}{*}{ Slope } & Controller & $\begin{array}{c}\text { Brake } \\
\text { release } \\
\text { delay }[\mathrm{s}]\end{array}$ & $\begin{array}{c}\text { Friction } \\
\text { work } \\
{[\mathrm{kJ}]}\end{array}$ & $\begin{array}{c}\text { *Starting } \\
\text { jerk [-] }\end{array}$ & $\begin{array}{c}\text { Rollback } \\
\text { distance } \\
{[\mathrm{m}]}\end{array}$ \\
\hline \multirow{3}{*}{$8 \%$} & Proposed & 0.11 & 124.46 & 1.03 & 0 \\
\cline { 2 - 6 } & Bang-bang & 0.25 & 126.16 & 1.06 & 0 \\
\cline { 2 - 6 } & Conventional & 0.79 & 142.81 & 1.14 & 0 \\
\hline \multirow{3}{*}{$13 \%$} & Proposed & 0.13 & 161.21 & 1.22 & 0 \\
\cline { 2 - 6 } & Bang-bang & 0.27 & 162.85 & 1.31 & 0 \\
\cline { 2 - 6 } & Conventional & 0.79 & 185.90 & 1.60 & 0 \\
\hline \multirow{3}{*}{$18 \%$} & Proposed & 0.12 & 236.63 & 1.65 & 0.005 \\
\cline { 2 - 6 } & Bang-bang & 0.29 & 239.89 & 1.75 & 0.005 \\
\cline { 2 - 6 } & Conventional & 0.79 & 273.15 & 2.06 & 0 \\
\hline
\end{tabular}

*RMS value

\subsection{Experiment}

To further verify the effectiveness of the logic threshold controller, the experiment is performed on a commercial vehicle equipped with EPB introduced in section 1 . The actual test vehicle employs the same parameters as those in Table 2. The experimental setup is shown in Fig. 13, the vehicle implements the HSA functionality on three different slopes, i.e., $20 \%, 13 \%$ and $8.2 \%$; the vehicle state signals are sent to CAN from the ECU of the EPB; a data acquisition program is developed in $\mathrm{PC}$ to acquire the real-time displaying and storing of the signals transmitted on CAN.

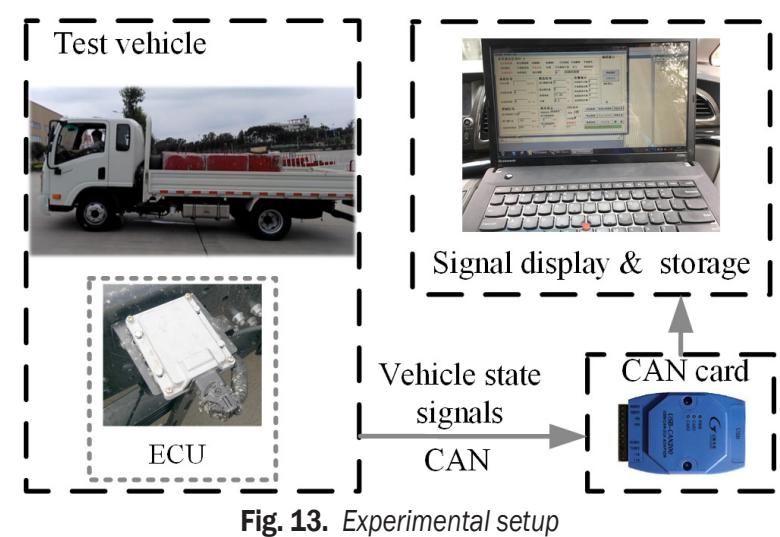

Fig. 14 shows the experimental results of $20 \%$ slope: at first, the vehicle is stopped on the gradient; as the driving torque increases, the driver's starting intention is confirmed by the system and the solenoid valve is therefore opened to inflate. With the proposed logic threshold control, the pressure increases with an increase in the desired pressure, triggering the corresponding PWM-PFM control of the solenoid valve when encountering different thresholds. The
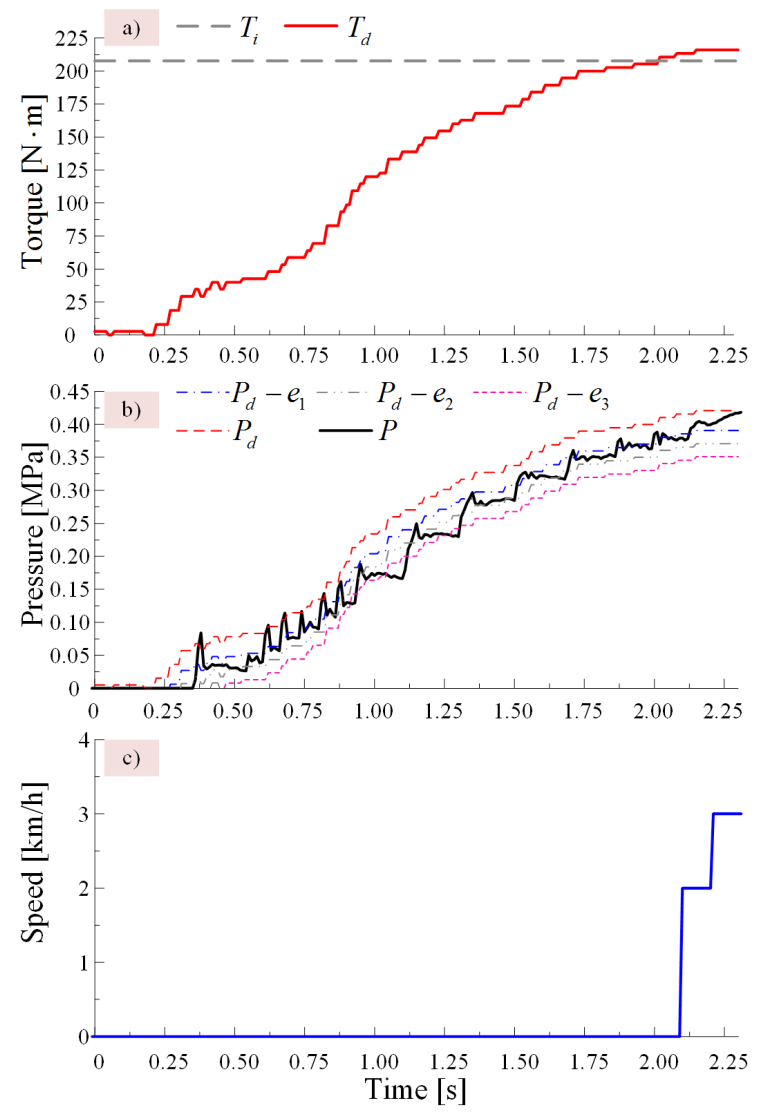

Fig. 14. Experiment results of $20 \%$ slope; a) torque, b) pressure, and c) speed 
driving torque overcomes the demand torque at 3.01 $\mathrm{s}$, and then, the EPB system rapidly inflates. After $3.10 \mathrm{~s}$, the vehicle velocity is gradually increased from 0 , implying a successful HSA implementation. The parking brake is completely released when the pressure reaches $0.4 \mathrm{MPa}$ at $3.15 \mathrm{~s}$ with a release delay of $0.14 \mathrm{~s}$, which is sufficiently small. The pressure follows the desired pressure effectively, and no rollback of the vehicle is observed during the entire hill-start process.

Similar experimental results can be found in Figs. 15 and 16. It is clear that the proposed controller enables the pressure to track the desired pressure effectively and the HSA functionality of EPB-equipped commercial vehicle is effectively implemented on 13 $\%$ and $8.2 \%$ slopes. A closer examination reveals that the release delay of the parking brake are $0.11 \mathrm{~s}$ and 0.09 s on $13 \%$ and $8.2 \%$ slope, respectively.

All of the above results demonstrate that the proposed logic threshold controller provides a satisfactory HSA performance of commercial vehicles equipped with $\mathrm{EPB}$, and the parking brake release delay is sufficiently small, thereby reducing the clutch wear and the starting jerk.
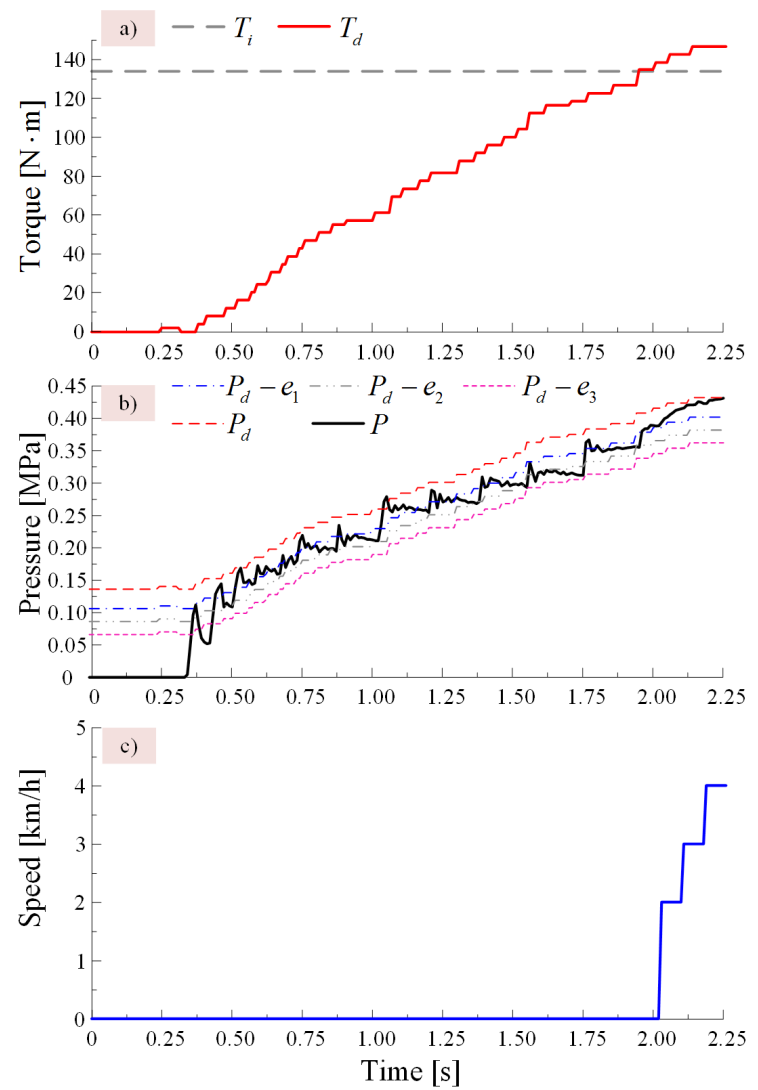

Fig. 15. Experiment results of $13 \%$ slope; a) torque, b) pressure, and c) speed

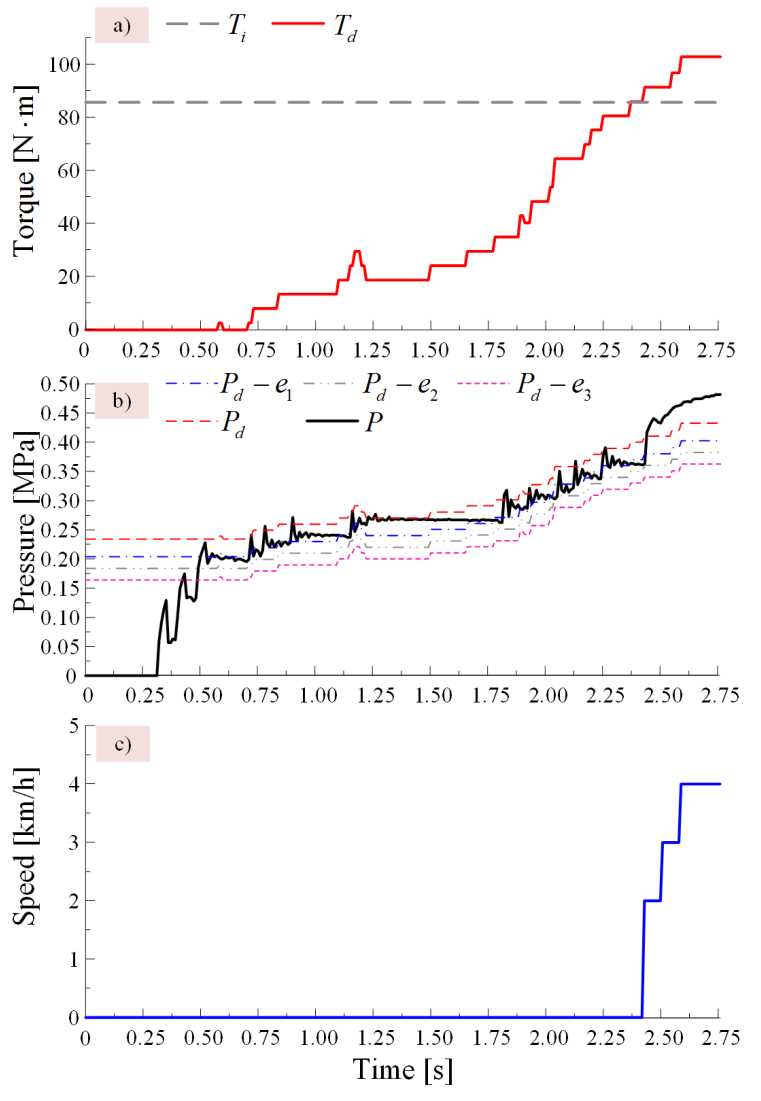

Fig. 16. Experiment results of $8.2 \%$ slope; a) torque, b) pressure, and c) speed

\section{CONCLUSIONS}

In this study, we developed a logic threshold control framework to improve the hill-start quality of EPBequipped vehicles under the prerequisite of safety start. In the control synthesis, the desired pressure model and EPB pneumatic system model were developed, and then, the proposed controller was constructed to control the solenoid valve according to the pressure error between the desired pressure and the actual pressure.

The simulation results verified the hill-start control effect, and the comparative results showed that the proposed controller outperformed the conventional and bang-bang controllers in terms of the brake release delay, friction work and starting jerk, which demonstrated that the proposed controller was capable of improving the hill-start quality of EPBequipped vehicles.

The vehicle experiment results further demonstrated that the proposed scheme could effectively implement the hill-start assist of the EPB- 
equipped vehicle without rollback and track the desired pressure with a small tracking error.

One direction to extend this work is to develop a recognition algorithm of the vehicle mass during the hill-start manoeuver to improve the identification precision and reduce cost.

\section{ACKNOWLEDGEMENTS}

This work was supported by the National Natural Science Fund of China (grant number 51205209,51205204), Project of Jiangsu Provincial Six Talent Peaks (grant number 2016-JXQC020), Fundamental Research Funds for the Central Universities (grant number 309171B8811), China Scholarship Council Funds (grant number 201606845008).

\section{NOMENCLATURES}

\begin{tabular}{|c|c|}
\hline$a$ & longitudinal acceleration, $\left[\mathrm{ms}^{-2}\right]$ \\
\hline$A_{c}$ & cross-sectional area of air gap, $\left[\mathrm{m}^{2}\right]$ \\
\hline$A_{s}$ & cross-sectional area of spool, $\left[\mathrm{m}^{2}\right]$ \\
\hline$c$ & viscous friction coefficient, [-] \\
\hline$e$ & pressure error, $[\mathrm{MPa}]$ \\
\hline$F_{i}$ & gradient resistance, $[\mathrm{N}]$ \\
\hline$F_{i \max }$ & maximal gradient resistance, $[\mathrm{N}]$ \\
\hline$F_{t}$ & driving force, $[\mathrm{N}]$ \\
\hline$F_{X b}$ & brake force, $[\mathrm{N}]$ \\
\hline$F_{X b \max }$ & maximal brake force, $[\mathrm{N}]$ \\
\hline$g$ & gravitational acceleration, $\left[\mathrm{ms}^{-2}\right]$ \\
\hline$i_{g}$ & transmission gear ratio, $[-]$ \\
\hline$i_{0}$ & differential ratio, $[-]$ \\
\hline$I$ & coil current, $[\mathrm{A}]$ \\
\hline$J$ & starting jerk, $\left[\mathrm{ms}^{-3}\right]$ \\
\hline$K_{s}$ & spring stiffness, $\left[\mathrm{Nm}^{-1}\right]$ \\
\hline$L$ & friction work, $[\mathrm{J}]$ \\
\hline$m$ & vehicle mass, $[\mathrm{kg}]$ \\
\hline$m_{s}$ & spool mass, $[\mathrm{kg}]$ \\
\hline$N$ & number of coils, [-] \\
\hline$P$ & actual pressure, $[\mathrm{MPa}]$ \\
\hline$P_{c r}$ & critical pressure ratio, $[-]$ \\
\hline$P_{d}$ & desired pressure, $[\mathrm{MPa}]$ \\
\hline$P_{d s}$ & downstream pressure, $[\mathrm{MPa}]$ \\
\hline$P_{\text {in }}$ & initial pressure, $[\mathrm{MPa}]$ \\
\hline$P_{s}$ & supply pressure, [MPa] \\
\hline$P_{u s}$ & upstream pressure, $[\mathrm{MPa}]$ \\
\hline$P_{0}$ & release pressure, $[\mathrm{MPa}]$ \\
\hline$\Delta P$ & pressure increase, $[\mathrm{MPa}]$ \\
\hline$r$ & tyre rolling radius, $[\mathrm{m}]$ \\
\hline$R$ & equivalent resistance, $[\Omega]$ \\
\hline$R_{g s}$ & ideal gas constant, [-] \\
\hline$S^{\circ}$ & PWM-PFM control signal, [-] \\
\hline
\end{tabular}

$t$

$t_{d}$

$t_{o}$

$T_{c}$

\section{$T_{d}$}

$T_{i}$

$U$

$x$

$x_{p}$

$\mu$

$\omega_{e}$

$\omega_{c}$

$\Phi$ lock-up time of the clutch, [s]

delay time, [s]

opening time, [s]

clutch torque, $[\mathrm{N} \cdot \mathrm{m}]$

driving torque, $[\mathrm{N} \cdot \mathrm{m}]$

demand torque, $[\mathrm{N} \cdot \mathrm{m}]$

driving voltage, [V]

spool displacement, [m]

spring pre-compression, [m]

air permeability, $\left[\mathrm{Hm}^{-1}\right]$

engine speed. $\left[\mathrm{r} \cdot \mathrm{min}^{-1}\right]$

speed of the clutch disk, $\left[\mathrm{r} \cdot \mathrm{min}^{-1}\right]$

magnetic flux, [Wb]

\section{REFERENCES}

[1] Sharma, A., Gangwar, H., Dabhole, D., Pathak, S., Dwivedi, V., and Nigam, A. (2016). Hill start assistance developed for buses equipped with AMT. SAE 2016 World Congress and Exhibition, DOl:10.4271/2016-01-1111.

[2] Balasubramanian, B. (2015). Sensor-less hill-assist using traction control in electric LCV. IEEE International Transportation Electrification Conference, p. 1-7, DOI:10.1109/ITEC-India.2015.7386921.

[3] Subramanian, S., Thangavel, P., Safna, F.M.I., Sornam, K., Rambhaji, G.P., Velusamy, R. (2015). Development and testing of a control algorithm to assist drive-off in the gradient-a rapid control prototyping approach. SAE Technical Paper, DOl:10.4271/2015-26-0002.

[4] Petrun, T., Flašker, J., Kegl, M. (2013). A Theoretical and numerical study of an additional viscosity term in a modified elasto-plastic friction model for wet friction clutch simulations. Strojniški vestnik - Journal of Mechanical Engineering, vol. 59, no. 7-8, p. 358-366, DOI:10.5545/sv-jme.2012.920.

[5] Kakinuma, Y., Aoyama, T., Anzai, H. (2007). Development of the variable friction clutch applying the functional medium. Strojniški vestnik - Journal of Mechanical Engineering, vol. 53, no. 11, p. 755-770.

[6] Ohkubo, N., Matsushita, S., Ueno, M., Akamine, K., Hatano, K. (2013). Application of electric servo brake system to plug-in hybrid vehicle. SAE International Journal of Passenger Cars Electronic and Electrical Systems, vol. 6, no. 1, p. 255-260, DOl:10.4271/2013-01-0697.

[7] Paulo, B., Claudinei, B., Alberto, B. (2013). Innovative hill start assistance device. 22nd SAE BRASIL International Congress and Display, p. 748-754.

[8] Ge, A., Lei, Y., Gao, Y., Zhang, H. A. (1998). A research on hill starting control of AMT system of vehicle. Automotive Engineering, vol. 20, no. 3, p. 150-155.

[9] Travaglia, C., de Souza, L., Ferreira, P., Ferreira, R. da Silva, M., de Abreu, L. (2015). Improved hill start aid system for commercial vehicles equipped with automated transmission, 24th SAE Brasil International Congress and Display.

[10] Lu, T., Dai, F., Zhang, J., Wu, M. (2012). Optimal control of dry clutch engagement based on the driver's starting intentions. Proceedings of the Institution of Mechanical Engineers, Part 
D: Journal of Automobile Engineering, vol. 226, no. 8, p. 10481057, D0l:10.1177/0954407011435465.

[11] Li, L., Zhu, Z., Wang, X., Yang, Y., Yang, C., Song, J. (2015). Identification of a driver's starting intention based on an artificial neural network for vehicles equipped with an automated manual transmission. Proceedings of the Institution of Mechanical Engineers, Part D: Journal of Automobile Engineering, vol. 230, no. 10, DOI:10.1177/0954407015611294.

[12] Gao, B.Z., Chen, H., Lu, X.H., Sanada, K. (2013). Improved optimal controller for start-up of AMT trucks in consideration of driver's intention. International Journal of Automotive Technology, vol. 14, no. 2, p. 213-220, Dol:10.1007/s12239. 013-0024-0.

[13] Wang, H.L., Yuan, Q.Z., Zhong, H.X., Pi, D.W. (2014). Research on the hill-start auto control for the vehicles with EPB. Transactions of Beijing Institute of Technology, vol. 34, no. 4, p. 344-348. (in Chinese)

[14] Delvecchio, D., Savaresi, S.M., Spelta, C., Dozio, S., Mandrioli, L., Cantoni, C. (2009). A control system for hill start assistance for commercial vehicles. ASME Dynamic Systems and Control Conference, p. 517-524, D0I:10.1115/DSCC2009-2728.

[15] Slosarczyk, K., Linden, J. G., Burnham, K. J., Cockings, K., Capolongo, R. (2008). Implementation of an electronic park brake feature with limited data availability. International Conference on Systems Engineering, p. 254-259, DOI:10.1109/ICSEng.2008.92.
[16] Wang, H.L., Gu, W.H., Zhang, Q.K., Wang, E.L. (2017). Research on bang-bang control of EPB system in vehicle hill start. Transactions of Beijing Institute of Technology, vol. 37, no. 1, p. 46-49, Dol:10.15918/j.tbit1001-0645.2017.01.010. (in Chinese)

[17] Wang, H.L., Li, M.Y., Jia, T.L. (2017). Vehicle mass measurement method and device based on suspension compression. Patent application CN 106679782 A, State Intellectual Property Office of the People's Republic of China, Beijing. (in Chinese)

[18] Wang, H.L., Zhang, Q.K., Gu, W.H. (2017). Simulation and experiment study on hill start control based on PID control. Automotive Engineering, vol. 39, no. 4, p. 480-485, D0I:10.19562/j.chinasae.qcgc.2017.04.017. (in Chinese)

[19] Kong, X.W., Li, S.Z. (2014). Dynamic performance of high speed solenoid valve with parallel coils. Chinese Journal of Mechanical Engineering, vol. 27, no. 4, p. 816-821, D0l:10.3901/CJME.2014.0513.091.

[20] He, L., Wang, X., Zhang, Y., Wu, J., Chen, L. (2011). Modeling and simulation vehicle air brake system. Proceedings $8^{\text {th }}$ Modelica Conference, p. 430-435, D0l:10.3384/ ecp11063430.

[21] Zhao, S., Hilmas, G.E., Dharani, L.R. (2008). Behavior of a composite multidisk clutch subjected to mechanical and frictionally excited thermal load. Wear, vol. 264, no. 11-12, p. 1059-1068, D0I:10.1016/J.wear.2007.08.012. 